\title{
The addition of duraplasty to posterior fossa decompression in the surgical treatment of pediatric Chiari malformation Type l: a systematic review and meta-analysis of surgical and performance outcomes
}

TO THE READERSHIP: An error appeared in the article by Lu et al. (Lu VM, Phan K, Crowley SP, et al: The addition of duraplasty to posterior fossa decompression in the surgical treatment of pediatric Chiari malformation Type I: a systematic review and meta-analysis of surgical and performance outcomes. J Neurosurg Pediatr 20:439-449, 2017).

In the Results section of the abstract, a $\mathrm{p}$ value was incorrectly given as $\mathrm{p}=0.0009$. The correct $\mathrm{p}$ value is $\mathrm{p}=$ 0.009 , as shown in the updated sentence below.

PFDD was associated with greater overall clinical improvement $(\mathrm{p}=0.009)$, along with longer length of stay $(\mathrm{p}<0.0001)$ and more postoperative complications $(\mathrm{p}=0.0001)$ compared with PFDO.

The article has been corrected online as of November 10, 2017.

Victor M. Lu, MBBS

Mayo Clinic, Rochester, MN

Sydney Medical School, University of Sydney, New South Wales,

Australia

INCLUDE WHEN CITING

Published online November 10, 2017; DOI: 10.3171/2017.10.PEDS16367a.

CAANS 2018, except where prohibited by US copyright law 